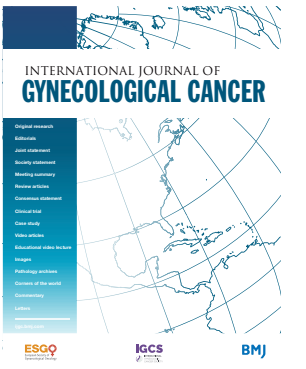

${ }^{1}$ Gynecology Oncology, La Fe University and Polytechnic Hospital, Valencia, Spain 2Department of Gynecology, Arnau de Vilanova University Hospital, Lleida, Spain ${ }^{3}$ Department of Colorectal Unit, La Fe University and Polytechnic Hospital, Valencia, Spain

Correspondence to Lourdes Sala Climent, Department of Gynecology, Arnau de Vilanova University Hospital, Lleida, Catalunya, Spain; salalourdes.275@gmail. com

Accepted 2 November 2021 Published Online First 16 November 2021

\title{
Ghost ileostomy: prevention, diagnosis, and early treatment of colorectal anastomosis leakage in advanced ovarian cancer
}

Victor Lago (D) , ${ }^{1}$ Lourdes Sala Climent (D) , ${ }^{2}$ Blanca Segarra-Vidal (D) , ${ }^{1}$ Matteo Frasson, ${ }^{3}$ Blas Flor, $^{3}$ Santiago Domingo (iD 1

In ovarian cancer, modified posterior pelvic exenteration and end-to-end colorectal anastomosis are usually necessary to achieve optimal cytoreduction. Anastomotic leak ranges from $1.7 \%$ to $6.8 \%$, and is the main life-threatening scenario after colorectal anastomosis. It has been associated with an increase in morbidity and mortality rates, days of hospitalization, and chemotherapy delays. ${ }^{1}$

With regard to the management after colorectal anastomosis, ghost ileostomy has been shown to be a good approach to reduce the rate of protective stoma. ${ }^{2}$ The use of ghost ileostomy in conjunction with close post-operative monitoring (C-reactive protein, procalcitonin, and rectoscopy) allows early and sub-clinical diagnosis of leakage. It can be easily converted into a diverting ileostomy if an anastomotic leakage is suspected, and only requires the loop removal for reversal. During the conversion into a diverting ileostomy it also allows a wash-up of the abdominal cavity to be done and the placement of a percutaneous drainage if indicated. Consequently, ghost ileostomy avoids the disadvantages associated with stoma such as dehydration, malnutrition, renal failure, prolapse, or stricture. Additionally, it also avoids the impact on self-image and quality of life associated with stoma. ${ }^{34}$

We present a case in which end-to-end colorectal anastomosis was performed due to an advanced

\section{GHOST ILEOSTOMY: PREVENTION, DIAGNOSIS, AND EARLY TREATMENT OF COLORECTAL ANASTOMOSIS LEAKAGE IN ADVANCED OVARIAN CANCER.}

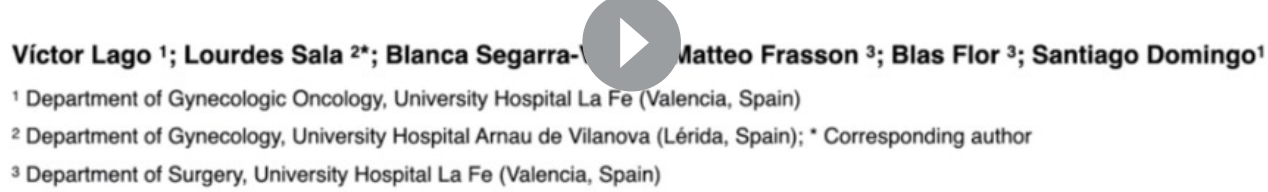

Check for updates

(C) IGCS and ESGO 2022. No commercial re-use. See rights and permissions. Published by BMJ.

\section{To cite: Lago V,} Sala Climent L, Segarra-Vidal B, et al. Int $\mathrm{J}$ Gynecol Cancer 2022;32:109110. 


\section{Video article}

ovarian cancer. A protective ghost ileostomy was performed as follows: a portion of terminal ileum $20 \mathrm{~cm}$ distant from the ileocecal valve was identified, the afferent and efferent portions were marked with a long and short stitch, and a vessel loop was placed from the mesenteric border to the abdominal wall at the point of the theoretical stoma. $^{23}$

Post-operatively, C-reactive protein and procalcitonin serum levels were monitored on post-operative days 1 and 3 , followed by a low pressure rectoscopy on day $4 .{ }^{1}$ Based on normal results, the patient started solid intake. At first defecation she had a sudden clinical worsening and an anastomotic leak was suspected. C-reactive protein and procalcitonin were measured and had risen from basal levels, and a sequential rectoscopy and a computed tomography-enterography showed an anastomotic leakage. Therefore, the ghost ileostomy was converted into a diverting ileostomy at an early clinical stage before fecal peritonitis was established and without re-laparotomy.

Ghost ileostomy represents a real option for tailoring the number of diverting ileostomies performed without increasing the morbidity and mortality. It is a reproducible, safe, and low-cost technique. ${ }^{34}$

Twitter Blanca Segarra-Vidal @BSegarraVidal

Contributors All the authors (VL, LS, BS, MF, BF, SD) have actively participated in the work providing input including: (1) substantial contributions to conception and study design, the guarantor in this case is $\mathrm{VL}$; (2) participation in the diagnosis and treatment, either in the surgery or in the endoscopic detection of anastomotic leak; (3) drafting of the article; and (4) final approval of the version to be published.

Funding The authors have not declared a specific grant for this research from any funding agency in the public, commercial or not-for-profit sectors.

Competing interests None declared.

Patient consent for publication Not applicable.

Provenance and peer review Not commissioned; externally peer reviewed.

Data availability statement All data relevant to the study are included in the article.

\section{ORCID iDs}

Victor Lago http://orcid.org/0000-0002-2971-1899

Lourdes Sala Climent http://orcid.org/0000-0003-2694-220X

Blanca Segarra-Vidal http://orcid.org/0000-0003-3203-0725

Santiago Domingo http://orcid.org/0000-0002-8355-3369

\section{REFERENCES}

1 Lago V, Fotopoulou C, Chiantera V, et al. Risk factors for anastomotic leakage after colorectal resection in ovarian cancer surgery: a multicentre study. Gynecol Oncol 2019;153:549-54.

2 Lago V, Sanchez-Migallón A, Flor B, et al. Comparative study of three different managements after colorectal anastomosis in ovarian cancer: conservative management, diverting ileostomy, and ghost ileostomy. Int J Gynecol Cancer 2019;29:1170-6.

3 Lago V, Flor B, Matute L, et al. Ghost ileostomy in advanced ovarian cancer: a reliable option. Int J Gynecol Cancer 2018;28:1418-26.

4 Lago V, Fotopoulou C, Chiantera V, et al. Indications and practice of diverting ileostomy after colorectal resection and anastomosis in ovarian cancer cytoreduction. Gynecol Oncol 2020;158:603-7. 